\title{
Pengaruh kinerja keuangan terhadap linkage non multifinance
}

\author{
Shihab Iqbal ${ }^{1 *}$, Deasy Tantriana \\ Fakultas Ekonomi Bisnis Islam UIN Surabaya \\ *Corresponding Author: shihabiqbal1996@gmail.com
}

Keywords:
Non-Performing Financing
(NPF), Ratio for Linkage
Financing, Non-Multi-Finance
Linkage.

DOI:

10.20885/JEKI.vol4.iss2.art5

\begin{abstract}
This study aims to determine the effect of NPF and profit-sharing ratio of linkage financing to non-multi-finance linkage at Bank BNI Syariah. The research method used in this study is a quantitative approach with the type of associative research. The result of this research shows that there are simultaneous effects of NPF and profit-sharing ratio on non-multi-finance linkage. It is also known that the partial correlation between NPF and non-multi-finance linkages shows a significant influence. Likewise, the partial correlation between profit-sharing ratio and non-multi-finance linkages shows a significant influence. Based on the result of this study, profit-sharing ratio is more dominant in influencing non-multi-finance linkage. The conclusion of this study is that NPF and profit-sharing ratio are important factors in policymaking of approving a non-multi-finance linkage financing. Therefore, it is necessary to pay close attention to the state of NPF and Profit-Sharing Ratio, thus there will be no error in making decisions regarding non-multi-finance linkage financing.
\end{abstract}

\begin{abstract}
Abstrak
Penelitian ini bertujuan untuk mengetahui pengaruh NPF dan nisbah bagi hasil pembiayaan linkage terhadap linkage non multifinance pada Bank BNI Syariah. Metode penelitian yang digunakan adalah pendekatan kuantitatif dengan jenis penelitian asosiatif. Hasil penelitian yang diperoleh adalah terdapat pengaruh secara simultan antara NPF dan nisbah bagi hasil terhadap linkage non multifinance. Diketahui juga bahwa korelasi parsial antara variabel NPF dengan linkage non multifinance menunjukkan adanya pengaruh signifikan. Begitu juga dengan korelasi parsial antara variabel nisbah bagi hasil dengan jumlah linkage non multifinance menunjukkan pegaruh yang signifikan. Berdasarkan hasil penelitian ini diketahui bahwa variabel nisbah bagi hasil lebih dominan dalam mempengaruhi linkage non multifinance. Kesimpulan dari penelitian ini adalah NPF dan nisbah bagi hasil merupakan faktor penting dalam mengambil kebijakan untuk memberikan pembiayaan linkage non multifinance. Maka dari itu perlu dicermati keadaan NPF dan Nisbah Bagi Hasil agar tidak terjadi kesalahan dalam mengambil keputusan pemberian pembiayaan linkage non multifinance.
\end{abstract}

\section{Pendahuluan}

Salah satu peran pebankan adalah menghubungkan pihak yang memiliki kelebihan dana untuk disalurkan kepada pihak yang membutuhkan pembiayaan. Melalui peran tersebut perbankan mampu menyalurkan pendanaan pada unit-unit usaha yang digunakan untuk melangsungkan produksi. Apabila keberlangsungkan produksi terjaga maka unit usaha dapat menoptimalkan pendapatan yan diperoleh. Keadaan ini akan meningkatkan tingkat pendapatan ekonomi secara agregat sehinga daya beli masyarakat meningkat.

Namun perbankan tidak bisa berperan sendiri dalam menyalurkan pendanan pada unit-unit usaha masyarakat dikarenakan proses pengelolaan pendanaan pada unit masyarakat memiliki karakter yang berbeda pada setiap jenis usaha sehingga model pengelola pendanan berbeda. Keterlibatan lembaga keuangan lain, seperti lembaga keuangan syariah (LKS) yang memiliki skala keuangan dan segmen mikro dibutuhkan agar pemanfaatan dana lebih optimal Oleh karenanya perbankan memiliki peran penting untuk mendorong pertumbuhan dan perkembangan LKS atau BMT melalui program pembiayaan linkage. Jenis pembiayaan tersebut merupakan pembiayaan yang bersifat kemitraan dan kerjasama antara pihak perbankan syariah sebagai pemilik dana dengan pihak LKS seperti Baitul Mal wat Tamwil (BMT) untuk diteruskan kepada para pengusaha mikro, kecil dan menengah. (Mi'raj, 2015)

Dengan adanya program pembiayaan linkage tersebut dapat memberikan manfaat kepada kedua belah pihak yaitu pihak perbankan dan pihak LKS. Diantaranya manfaat untuk pihak perbankan yaitu mendapatkan kepastian pembiayaan kepada mitra binaannya dan mendapatkan ujrah/fee dari pihak LKS, sedangkan manfaat bagi LKS yaitu dapat mengembangkan/meningkatkan produktifitasnya diantaranya dapat membantu meningkatkan pemberdayaan lembaga keuangan syariah di Indonesia sebagai lembaga keuangan mikro, menjadi sumber 
pendanaan tambahan bagi lembaga keuangan syariah (funding), meningkatkan kepercayaan perbankan terhadap LKS, serta mempercepat pemerataan penyaluran dana syariah kepada usaha mikro kecil dan menengah dalam hal membantu mengentaskan kemiskinan.(Hamidah, 2016).

Pada dasarnya pembiayaan linkage menggunakan akad muḍārabah yang membutuhkan rasa saling percaya cukup tinggi antara pemilik dana dan pengelola dana. Selain itu, pembagian keuntungan harus dalam bentuk nisbah/persentase yang telah disepakati. Dalam muḍārabah keuntungan disebut nisbah bagi hasil karena besarnya keuntungan yang akan diterima oleh pemilik dana dan pengelola dana belum bisa diketahui dengan pasti, karena besarnya keuntungan yang akan diterima tergantung pada laba yang dihasilkan.

Di Indonesia pembiayaan linkage juga diterapkan dalam perbankan syariah, salah satu perbankan yang menerapkan program pembiayaan linkage adalah BNI Syariah. BNI Syariah sendiri berdiri pada tanggal $21 \mathrm{Mei}$ 2010 dengan modal dasar sebesar Rp. 4 trilliun. Hingga bulan Juni 2014, jumlah cabang BNI Syariah mencapai 65 Kantor Cabang, 161 Kantor Cabang Pembantu, 17 Kantor Kas, 22 Mobil Layanan Gerak dan 20 Payment Point. Bank BNI Syariah terdapat produk pembiayaan linkage dengan nama pembiayaan kerjasama linkage program IB Hasanah. Definisi linkage program menurut BNI Syariah yaitu sebuah fasilitas pembiayaan dimana BNI Syariah sebagai pemilik dana menyalurkan pembiayaan dengan pola executing kepada lembaga keuangan syariah (LKS) seperti BMT, BPRS, KJKS, dll untuk diteruskan kepada end user, seperti pengusaha mikro, kecil, dan menengah syariah.

Pola executing sendiri merupakan pinjaman yang diberikan oleh bank umum syariah kepada lembaga keuangan syariah dalam rangka pembiayaan untuk disalurkan kembali kepada anggota lembaga keuangan syariah atau end user. Pencatatan di bank umum syariah sebagai pembiayaan dengan akad mud̄arabah kepada lembaga keuangan syariah, sedangkan pencatatan di lembaga keuangan syariah sebagai pembiayaan kepada anggota lembaga keuangan syariah sesuai dengan kebutuhan anggota. (Dafta, 2012).

Tabel 1. Komposisi NPF, Nisbah Bagi Hasil, dan Linkage Non Multifinance

\begin{tabular}{cccc}
\hline Tahun & $\begin{array}{c}\text { NPF } \\
(\%)\end{array}$ & $\begin{array}{c}\text { Nisbah } \\
\text { Bagi Hasil }\end{array}$ & $\begin{array}{c}\text { Linkage Non Multifinance } \\
\text { (dalam jutaan) }\end{array}$ \\
\hline $\mathbf{2 0 1 2}$ & $1,42 \%$ & $65 \%$ & 287.064 \\
$\mathbf{2 0 1 3}$ & $1,13 \%$ & $58 \%$ & 709.218 \\
$\mathbf{2 0 1 4}$ & $1,04 \%$ & $59 \%$ & 1.041 .245 \\
$\mathbf{2 0 1 5}$ & $1,46 \%$ & $66 \%$ & 1.279 .950 \\
$\mathbf{2 0 1 6}$ & $1,64 \%$ & $71 \%$ & 1.198 .408 \\
\hline Sumbr
\end{tabular}

Sumber: Bank BNI Syariah 2012-2016 dan Anual Report BNI Syariah 2011-2013

Dari tabel 1 komposisi linkage non multifinance tidak terlepas dengan adanya NPF dan nisbah bagi hasil pada tahun 2012-2016. Dapat dilihat pada tabel komposisi linkage non multifinance periode 2012-2016 mengalami peningkatan dan penurunan di tahun tertentu. Peningkatan dan penurunan ini merupakan dampak langsung dari perkembangan berbagai faktor salah satunya tingkat Non Performing Financing (NPF) dan nisbah bagi hasil di bank BNI Syariah.

Linkage non multifinance yaitu program pembiayaan linkage yang dilakukan antara pihak bank syariah dengan lembaga keuangan syariah non multifiance. Pada perkembangan saat ini, terdapat indikasi bahwa NPF dan nisbah bagi hasil dapat mempengaruhi jumlah linkage non multifinance. Di dalam dunia perbankan syariah, faktor tersebut tidak terlepas dari besarnya tingkat pembiayaan dan kualitas asset bank yang tercermin dalam tingkat NPF. Tingginya NPF, khususnya pembiayaan yang macet memberikan kontribusi besar pada buruknya kinerja perbankan.

Multifinance merupakan sebuah lembaga keuangan non bank yang melakukan kegiatan pembiayaan dalam bentuk penyediaan dana atau barang modal yang termasuk dalam aktiva tetap berwujud. Dengan kata lain, lembaga multifinance ini melakukan kegiatan pembiayaan atau menjamin kepada customer atas aktiva tetap berwujud yang dipakai oleh customer tersebut. Akan tetapi lembaga multifinance masih memiliki hak atas aktiva tetap berwujud yang dipakai oleh customer. Sehingga, multifinance dapat disebut sebagai pihak customer dengan penyedia barang (suplier). Dalam jangka waktu tertentu, customer dapat memiliki hak milik atas aktiva tetap berwujud sesuai dengan perjanjian yang telah disepakati.(Suryani, 2017)

Pertumbuhan pembiayaan di Indonesia relatif besar jika dibandingkan dengan negara-negara Asia lainnya. Dengan melihat pertumbuhan yang cukup besar tersebut, apalagi pembiayaan merupakan salah satu aktivitas bisnis utama perbankan syariah, perlu ada pengelolaan yang baik. Pengelolaan pembiayaaan perbankan merupakan salah satu indikator keberhasilan dalam mengelola bisnis perbankan. Bank syariah yang dapat mengelola pembiayaannya dengan baik dapat menghasilkan NPF pada level yang rendah dengan memberikan kontribusi laba yang tinggi. Akan tetapi jika bank syariah tidak dapat mengelola pembiayaannya dengan baik maka dapat menghasilkan NPF pada level yang tinggi. Menurut Zaenuri, 2015, apabila terjadi peningkatan 
jumlah pembiayaan bermasalah maka dapat menurunkan jumlah pembiayaan. Hal ini juga termasuk jumlah pembiayaan linkage non multifinance.

Sistem bagi hasil (profit and loss sharing) yang diterapkan dalam perbankan syariah merupakan praktek perkongsian yang sudah lazim digunakan sebelum agama Islam datang di dataran Timur Tengah. Kemitraankemitraan bisnis yang berdasarkan atas konsep mudharabah dan musyarakah berjalan berdampingan dengan konsep pinjam sistem bunga sebagai cara untuk membiayai berbagai aktivitas ekonomi. Kemudian setelah islam datang, semua transaksi keuangan yang berbasis riba dilarang dan semua dana harus disalurkan atas dasar bagi hasil (profit and loss sharing) (Syahroni, 2018). Bagi hasil adalah suatu sistem yang meliputi tata cara pembagian hasil usaha antara penyedia dana dan pengelola dana.(Rofiq, 2004). Pada mekanisme perbankan syariah, pendapatan bagi hasil ini berlaku untuk produk-produk penyertaan, baik penyertaan menyeluruh maupun sebagian-sebagian, atau bentuk bisnis korporasi (kerjasama). Pihak-pihak yang terlibat dalam kepentingan bisnis yang disebut tadi, harus melakukan transparansi dan kemitraan secara baik dan ideal. Sebab semua pengeluaran dan pemasukan rutin untuk kepentingan pribadi yang menjalankan proyek.(Muhammad, 2004)

Nisbah bagi hasil merupakan suatu perjanjian penentuan proporsi pembagian hasil usaha yang akan diterima kedua belah pihak yang melakukan perjanjian. Tingginya tingkat nisbah bagi hasil yang dibagikan akan memengaruhi linkage non multifinance. Menurut Zaenuri, (2015), semakin besar jumlah pendapatan bagi hasil yang diterima oleh bank maka semakin besar pula keinginan bank untuk memberikan pembiayaan bagi hasil. Sebaliknya semakin kecil jumlah pendapatan bagi hasil yang diterima oleh bank maka akan semakin kecil keinginan bank untuk memberikan pembiayaan bagi hasil". Bank syariah harus bisa mengoptimalkan pembiayaan linkage non multifinance supaya mampu memperoleh pendapatan serta keuntungan yang tinggi dari pembiayaan mud̄ārabah. Jadi, bank syariah harus mampu mengelola dana yang telah diinvestasikan oleh masyarakat di bank syariah dalam bentuk pembiayaan linkage non multifinance.

\section{Metode Penelitian}

Penelitian ini merupakan penelitian kuantitatif yang analisisnya lebih fokus pada data-data yang diolah dengan menggunakan metode statisttika. Adapun jenis penelitian dari penelitian ini adalah asosiatif. Jenis penelitian asosiatif adalah penelitian dengan menjelaskann hubungan antara variabel $x$ dengan variabel $y$. Sedangkan populasi adalah jumlah keseluruhan dari satuan-satuan atau individu-individu yang karakteristiknya hendak diteliti. Dan satuan-satuan tersebut dinamakan unit analisis, dan dapat berupa orang-orang, institusi-institusi, benda-benda, dst (Kuntjojo, 2009). Populasi dalam penelitian ini adalah seluruh data time series bulanan NPF, nisbah bagi hasil pembiayaan linkage dan jumlah pembiayaan linkage non multifinance BNI Syariah. Sedangkan yang diambil adalah periode data time series bulanan NPF, nisbah bagi hasil pembiayaan linkage dan jumlah pembiayaan linkage non multifinance BNI Syariah 2012 sampai 2016.

Dalam penelitian ini memberlakukan dua jenis variabel yang menjadi obyek penelitian, yaitu: Independen variable yaitu variabel yang mempengaruhi dan mempunyai suatu hubungan dengan variabel yang lain. Variabel independen dalam penelitian ini yaitu NPF dan nisbah bagi hasil. Variabel dependen yaitu linkage non multifinance. Data yang digunakan untuk mengetahui hubungan dari variabel-variabel yang akan diteliti. Dalam pengujian ini menggunakan uji Statistik meliputi Uji-t dan Uji-F. Uji t digunakan untuk menguji apakah setiap variabel independen secara masing-masing parsial atau individual memiliki pengaruh yang signifikan terhadap variabel terikat dependen pada tingkat signifikansi $0,05(5 \%)$ dengan menganggap variabel bebas bernilai konstan. (Nachrowi \& Usman, 2006)

Nilai F hitung digunakan untuk menguji ketetapan model (goodness of fit). Uji F ini juga sering disebut uji simultan, untuk menguji apakah variabel bebas yang digunkan dalam model mampu menjelaskan perubahan nilai variabel terikat atau tidak. Adapun cara pengujian dalam uji $\mathrm{F}$ ini. yaitu dengan menggunakan suatu variabel yang disebut dengan tabel ANOVA (Analysis of Variance) dengan melihat nilai signifikan (Sig. $<0,05$ atau $5 \%$ ). $\mathrm{F}_{\text {hitung }} \leq \mathrm{F}_{\text {tabel }}$ maka Ho diterima dan $\mathrm{H}_{1}$ ditolak. Sedangkan Jika $\mathrm{F}_{\text {hitung }}>\mathrm{F}_{\text {tabel }}$ maka Ho ditolak dan $\mathrm{H}_{1}$ diterima. (Widarjono, 2010). Adapun persamaan dalam peneltian ini dapat ditulis sebagai berikut;

Linkage Non Multifinance $=\mathrm{a}+\mathrm{b}_{1} \mathrm{NPF}+\mathrm{b}_{2}$ Nisbah Bagi Hasil $+\mathrm{e}$

Dimana, linkage non multifinance adalah linkage non multifinance pada BNI Syariah, a adalah intercept (konstanta), b adalah koefisien regresi dari variabel independen, NPF adalah nonperformance finance, nisbah bagi hasil adalah rasio bagi hasil antara bank dan mitra. dan e adalah nilai residu. 


\section{Hasil dan Pembahasan}

Uji normalitas yang digunakan dalam penelitian ini adalah menggunakan uji Kolmogorov-Smirnov dengan melihat nilai kolmogorov-smirnov Z. Jika nilai kolmogorov-smirnov Z lebih besar dari nilai derajat kesalahan $\alpha=$ $5 \%$ (0.05), maka penelitian ini dikatakan tidak ada permasalahan normalitas atau dengan kata lain data terdistribusi normal. Dan sebaliknya, jika nilai kolmogorov-smirnov Z lebih kecil dari nilai derajat kesalaan $\alpha=5$ $\%(0,05)$, maka dalam penelitian ada permasalahan normalitas atau data tidak terdistribusi dengan normal.

Berdasarkan perbandingan antara $\mathrm{F}_{\text {hitung }}$ dan $\mathrm{F}_{\text {tabel }}$ dapat disimpulkan bahwa Non Performing Financing (NPF) dan nisbah bagi hasil pembiayaan linkage berpengaruh secara simultan terhadap linkage non multifinance hal ini dapat dilihat dengan hasil $\mathrm{F}_{\text {hitung }}$ sebesar 8,975 dan $\mathrm{F}_{\text {tabel }}$ sebesar 5,7 yang berarti $\mathrm{F}_{\text {hitung }}>\mathrm{F}_{\text {tabel }}$ maka Ho ditolak

Tabel 1. Model Summary Regresi Linear Berganda

\begin{tabular}{lccrr}
\hline Model & $\mathrm{R}$ & R Square & Adjusted R Square & Std. Error of the Estimate \\
\hline 1 &, $489^{\mathrm{a}}$ &, 239 &, 213 & 320623,45923 \\
\hline a. Predictors: (Constant), Nisbah Bagi Hasil Pembiayaan Linkage, NPF & \\
\hline
\end{tabular}

Nilai R Square pada tabel model summary ini adalah 0,239 hal ini berarti 23,9\% variasi dari variabel jumlah pembiayaan muḍārabah bisa dijelaskan oleh oleh variasi dari variabel NPF dan nisbah bagi hasil pembiayaan linkage. sedangkan sisanya yaitu $76,1 \%$ dijelaskan oleh sebab yang lainnya. Sedangkan Standard Error of Estimate (SEE) senilai 320623. Semakin kecil nilai SEE maka semakin tepat dalam memprediksi variabel dependen.

Hasil perhitungan diketahui bahwa secara parsial terdapat dua variabel independen yang berpengaruh yaitu NPF dan nisbah bagi hasil pembiayaan linkage. Berdasarkan pengujian variabel NPF dapat dilihat bahwa nilai yang di dapat dari nilai t untuk variabel NPF sebesar 0,457 dengan nilai signifikansi 0,002. Dapat disimpulkan bahwa NPF berpengaruh secara signifikan terhadap jumlah linkage non multifinance. Serta pengujian variabel nisbah bagi hasil pembiayaan linkage dapat dilihat bahwa nilai yang di dapat dari nilai t untuk variabel nisbah bagi hasil pembiayaan linkage sebesar 0,561 dengan nilai signifikansi 0,000. Dapat disimpulkan bahwa nisbah bagi hasil pembiayaan linkage berpengaruh secara signifikan terhadap jumlah linkage non multifinance.

Tabel 2. Uji T

\begin{tabular}{|c|c|c|c|c|c|c|}
\hline \multirow{2}{*}{\multicolumn{2}{|c|}{ Model }} & \multicolumn{2}{|c|}{ Unstandardized Coefficients } & \multirow{2}{*}{$\begin{array}{c}\text { Standardized } \\
\text { Coefficients } \\
\text { Beta } \\
\end{array}$} & \multirow[t]{2}{*}{$\mathrm{T}$} & \multirow[t]{2}{*}{ Sig. } \\
\hline & & $\mathrm{B}$ & Std. Error & & & \\
\hline \multirow{3}{*}{1} & (Constant) & $-592087,168$ & 552704,698 & & $-1,071$ & ,289 \\
\hline & NPF & $-844334,782$ & 256442,172 &,- 457 & $-3,292$ & ,002 \\
\hline & $\begin{array}{l}\text { Nisbah Bagi Hasil } \\
\text { Pembiayaan Linkage }\end{array}$ & 41922,437 & 10371,672 & ,561 & 4,042 & ,000 \\
\hline
\end{tabular}

a. Dependent Variable: Jumlah Pembiayaan Linkage Non Multifinance

Dari tabel di atas dapat kita lihat pada kolom Unstandardized Coefficients Beta yang menunjukkan model persamaan regresi linear berganda untuk memperkirakan jumlah linkage non multifinance yang dipengaruhi oleh NPF dan nisbah bagi hasil pembiayaan linkage adalah:

$\mathrm{Y}=-592087,168+-844334,782+41922,437+0$

Dimana, $\mathrm{Y}$ adalah variabel tergantung atau terikat (nilai yang diproyeksikan), a adalah intercept (konstanta), $\mathrm{b}_{1}$ adalah koefisien regresi untuk $\mathrm{X}_{1}, \mathrm{~b}_{2}$ adalah koefisien regresi untuk $\mathrm{X}_{2}, \mathrm{X}_{1}$ adalah variabel bebas pertama, $\mathrm{X}_{2}$ adalah variabel bebas kedua dan e adalah nilai residu.

Dari persamaan regresi linear berganda di atas dapat kita lihat beberapa hal diantaranya sebagai berikut: Nilai konstanta dari persamaan diatas yaitu $-592087,168$. Nilai tersebut dapat disimpulkan bahwa jumlah linkage non multifinance akan bernilai -592087,168 satuan jika variabel NPF dan nisbah bagi hasil pembiayaan linkage tidak ada. Sedangkan nilai koefisien regresi NPF sebesar $-844334,782$. Nilai koefisien negatif berarti NPF berpengaruh negatif terhadap jumlah linkage non multifinance, dapat diartikan bahwa semakin besar jumlah NPF maka semakin kecil jumlah linkage non multifinance. Dan terakhir nilai koefisien regresi nisbah bagi hasil pembiayaan linkage sebesar 41922,437. Nilai koefisien positif berarti nisbah bagi hasil pembiayaan linkage 
berpengaruh positif terhadap jumlah linkage non multifinance, dapat diartikan bahwa semakin besar jumlah nisbah bagi hasil pembiayaan linkage maka semakin besar pula jumlah linkage non multifinance.

Tabel 3. Coefficient

\begin{tabular}{llrrrrr}
\hline Model & & \multicolumn{2}{c}{ Unstandardized Coefficients } & $\begin{array}{c}\text { Standardized } \\
\text { Coefficients } \\
\text { Beta }\end{array}$ & $\mathrm{t}$ & Sig. \\
& \multicolumn{1}{c}{ B } & Std. Error & & \\
\hline \multirow{2}{*}{1} & (Constant) & $-592087,168$ & 552704,698 & & $-1,071$ &, 289 \\
& NPF & $-844334,782$ & 256442,172 &,- 457 & $-3,292$ &, 002 \\
& $\begin{array}{l}\text { Nisbah Bagi Hasil } \\
\text { Pembiayaan Linkage }\end{array}$ & 41922,437 & 10371,672 &, 561 & 4,042 &, 000 \\
\hline
\end{tabular}

a. Dependent Variable: Jumlah Pembiayaan Linkage Non Multifinance

Hasil dari pengujian statistik yang dilakukan, dapat diketahui bahwa regresi yang dihasilkan cukup baik untuk menerangkan variabel-variabel yang dapat mempengaruhi jumlah pembiayaan linkage non multifinance. Variabel NPF dan nisbah bagi hasil pembiayaan linkage yang dimasukkan ke dalam pengujian statistik ternyata tidak semua variabel berpengaruh secara signifikan.

Hasil pengujian variabel NPF dapat dilihat bahwa nilai yang di dapat dari nilai t untuk variabel NPF sebesar -0,457 dengan nilai signifikansi 0,002. NPF berpengaruh secara signifikan terhadap jumlah linkage non multifinance. Hal ini menunjukan bahwa dalam perbankan syariah NPF merupakan hal yang berusaha akan terus ditekan, karena dapat mengurangi modal perbankan jika terus bertambah dan otomatis mengurangi jumlah pembiayaan yang diberikan. Sedangkan kolerasi parsial antara variabel nisbah bagi hasil pembiayaan linkage dapat dilihat bahwa nilai yang di dapat dari nilai t untuk variabel nisbah bagi hasil pembiayaan linkage sebesar 0,561 dengan nilai signifikansi 0,000 .

Dapat disimpulkan bahwa nisbah bagi hasil pembiayaan linkage berpengaruh secara signifikan terhadap jumlah linkage non multifinance. Bank syariah harus bisa mengoptimalkan pembiayaan linkage non multifinance supaya mampu memperoleh pendapatan serta keuntungan yang tinggi dari pembiayaan muḍārabah. Jadi, bank syariah harus mampu mengelola dana yang telah diinvestasikan oleh masyarakat di bank syariah dalam bentuk pembiayaan linkage non multifinance.

Berdasarkan hasil penelitian ini diketahui bahwa terdapat pengaruh secara simultan antara NPF dan nisbah bagi hasil pembiayaan linkage terhadap jumlah pembiayaan linkage non multifinance. Hal ini dapat dilihat dari Uji F yang menyatakan bahwa $F_{\text {hitung }}=8,972>F_{\text {tabel }}=5,7$ yang berarti bahwa Ho ditolak, maka dabat disismpulkan bahwa terdapat pengaruh secara simultan antara NPF dan nisbah bagi hasil pembiayaan linkage terhadap jumlah pembiayaan linkage non multifinance.

Dari hasil analisis data, dapat dilihat bahwa NPF berpengaruh negatif dan nisbah bagi hasil berpengaruh positif terhadap pembiayaan linkage non multifinance. Hal ini bisa menunjukkan bahwa semakin besar jumlah pendapatan bagi hasil yang diterima oleh bank maka semakin besar pula keinginan bank untuk memberikan pembiayaan bagi hasil. Sebaliknya semakin kecil jumlah pendapatan bagi hasil yang diterima oleh bank maka akan semakin kecil keinginan bank untuk memberikan pembiayaan bagi hasil.

Di dalam penelitian ini, variabel NPF dan nisbah bagi hasil hanya mampu menjelaskan 30,2\% dari linkage non multifinance. Hal ini dapat dilihat dari tabel regresi linier berganda (model summary) pada kolom $\mathrm{R}$ square. Sedangkan sisanya, yakni sebesar 69,8\% dijelaskan oleh variabel lain. Selain itu variabel lainnya yang mungkin bisa menjelaskan variabel linkage non multifinance adalah dana pihak ketiga, Capital Adequacy Ratio (CAR), dan Return On Asset (ROA). Seperti yang terdapat pada penelitian yang dilakukan oleh Wahidahwati (2016), dimana variabel independennya dapat menjelaskan variabel dependennya sebesar 68,7\%. Hasil DPK dan CAR berpengaruh signifikan positif terhadap pembiayaan mudārabah. Sedangkan ROA dan BOPO berpengaruh signifikan negatif terhadap pembiayaan mud̄arabah dan NPF tidak berpengaruh signifikan terhadap pembiayaan mudāarabah dengan arah positif.

\section{Kesimpulan}

NPF berpengaruh negatif terhadap tingkat pembiayaan BNI syariah pada pembiayaan linkage non multifinance. Keadaan ini menunjukkan manajemen BNI syariah mempertimbangkan tingkat NPF sebagai salah satu variabel yang dijadikan dasar dalam menentukan besaran pembiayaan. Upaya yang dilakukan manajemen BNI syariah untuk menekan resiko pembiayaan adalah melihat tingkat NPF periode pembiayaan dan dengan melihat kelayakan mitra yang mengajukan pembiayaan. Sementara itu, manajemen BNI syariah menentukan rasio 
pembagian hasil kepada mitra atau pihak yang mengajukan pembiayaan linkage non multifinance disesuaikan dengan besar pembiayaan. Semakin tinggi nilai pembiayaan linkage non multifinance semakin tinggi rasio bagi hasil yang diberikan kepada mitra. Keadaan ini menunjukkan bahwa BNI Syariah dan pihak mitra dalam posisi saling membutuhkan dan saling mendapatkan untung dari kemitraan yang terbentuk. Dari hasil penelitian ini direkomendasikan agar penelitian yang akan datang dengan topik yang sama mengunakan variabel kinerja keuangan bank, seperti variabel DPK, CAR dan BOPO.

\section{Daftar Pustaka}

Dafta, F, A (2012), Perbedaan Pola Channeling dan Executing pada Pembiayaan Lingkage Program di Bank Syariah Mandiri Cabang Salatiga, Jurnal Muqtashid, 3(2), 251-276

Hamidah, S. (2016), Analisis Kebijakan Lingkage Program Lembaga Keuangan Syariah dalam Rangka Pemberdayaan UKM di Indonesia, Arena Hukum, 8(2), 147-399

Kuntjojo. (2009). Metodologi Penelitian. Kediri: Universitas Nusantara.

Mi'raj, D,A, (2015). Lingkage Program bank Syariah dengan BMT: Tinjauan Kritis bagi Pengembangan Sistem Keuangan Islam yang Lebih Kaffah, JESTT, 2(10), 850-864

Muhammad. (2004). Teknik Perhitungan Bagi Hasil di Bank Syari'ah. Yogyakarta: UII Press.

Nachrowi, D. N., \& Usman, H. (2006). Pendekatan Populer dan Praktis Ekonometrika untuk Analisis dan Keuangan,. (Ghalia Indonesia, Ed.). Jakarta.

Rofiq, A. (2004). Fiqih Kontekstual dari Normatif ke Pemaknaan Sosial,. Yogyakarta: Pystaka Pelajar.

Suryani, I. (2017). Pengertian Multifinance dan Leasing. Retrieved from http://irmasuryani290.blogspot.co.id/2014/3/pengertian-multifinance-dan-leasing.html?m.

Syahroni, M. I. (2018). "Muḍārabah dan Musyarakah serta implementasinya dalam perbankan islam. Retrieved from https://ayahaca.wordpress.com/2011/06/06/34/,

Wahidahwati, J. (2016). Faktor-Faktor yang Mempengaruhi Pembiayaan Muḍārabah pada Bank Umum Syariah di Indonesia. Jurnal Ilmu Dan Riset Akuntansi, 5(4), 19-27.

Widarjono A, (2010) Ekonometrika Pengantar dan Aplikasinya, Yogjakarta: Ekonesia.

Zaenuri, W. (2015). Analisis Pengaruh FDR, NPF, Tingkat Bagi Hasil, Kulitas Jasa, dan Atribut Produk Islam terhadap Tingkat Pembiayaan Muḍārabah. Jurnal Ekonomi Dan Bisnis Islam IAIN Walisongo Semarang, 2(5), 121-134. 